\title{
Altered Coagulation Pattern in Different Histological Grades of Squamous Cell Carcinoma
}

\author{
Kiran Shaikh ${ }^{1}$, Ghulam Shah Nizamani ${ }^{2}$, Yar Muhammad Nizamani ${ }^{3}$, Naila Nizamani ${ }^{4}$, Amin Fahim ${ }^{5}$, \\ Farkhunda Nadeem ${ }^{2}$ \\ ${ }^{1}$ Lecturer, Department of Pathology, Isra University Hyderabad, Pakistan \\ ${ }^{2}$ Professor, Department of Pathology, Isra University Hyderabad, Pakistan \\ ${ }^{3}$ Assistant Professor, Department of Physiology, Isra University Hyderabad, Pakistan \\ ${ }^{4}$ PhD Scholar, Isra University Hyderabad, Pakistan \\ ${ }^{5}$ Associate Professor, Department of Pathology, Isra University Hyderabad, Pakistan
}

\begin{abstract}
A BST RACT
Background: The incidence of squamous cell carcinoma has doubled in the last three decades associated with a high rate of morbidity and mortality. The incidence of bleeding and/or thrombosis in advanced stage cancer necessitates a need for research in blood coagulation abnormalities in malignancy. The objective of the present study was to determine the alteration in coagulation pattern among patients diagnosed with squamous cell carcinoma (SCC).

Material and Methods: This cross-sectional study was conducted in Pathology department of Isra University Hospital, Hyderabad over a period of 06 months. A total of 126 samples were selected through non-probability convenient sampling. Both male and female patients of all age groups having SCC of skin, gastrointestinal and genital tract were included. The coagulation profile was analyzed by Sysmax CA 50 and Nycocard reader II. Data was entered into SPSS version 22.0 and results were analyzed.

Results: The mean age of the patients with SCC in the present study was $55.5 \pm 12$ years with more male patients $(n=81 ; 64.3 \%)$ as compared to females ( $n=45 ; 35.7 \%)$. Oral SCC was found to be the most common site of squamous cell carcinoma (43.7\%). Majority of the patients had well differentiated SCC (42.1\%) followed by moderately differentiated (40.5\%) and poorly differentiated SCC (17.4\%). The comparison of severity of SCC with coagulation profile revealed that PT $(P=0.01)$, APTT $(P=0.001)$, D-dimers $(P=0.01$ and TT $(P=0.01)$ were significantly increased, whereas fibrinogen was significantly decreased $(P=0.001)$.

Conclusions: The histological differentiation of SCC (from well differentiated to poorly differentiated tumors) showed a highly significant association with different coagulation profile parameters like PT, APTT, BT, CT, D-dimer, TT, and fibrinogen levels.

Key words: Coagulation, D-Dimers, Fibrinogen, Prothrombin time, Squamous cell carcinoma, Thrombin

Authors' Contribution: Correspondence:

manuscript design and drafting; ${ }^{4-6}$ Critical Email:draminfahim@gmail.com Received: February 6, 2019

analysis and manuscript review. Data

Accepted: June 22, 2020 analysis; Manuscript Editing.

Cite this article. Shaikh K, Nizamani GS, Nizamani YM, Nizamani N, Fahim A, Nadeem F. Altered Coagulation Pattern in Different Histological Grades of Squamous Cell Carcinoma. J Funding Source: Nil Islamabad Med Dental Coll.2020; 9(2): 123-128. Doi: 10.35787/jimdc.v9i2.281
\end{abstract}

\section{Introduction}

Squamous cell carcinoma is the second most common malignancy of skin. It also arises from head and neck, vagina, cervix and anus. ${ }^{1}$ The prostate, urinary bladder, esophagus and lung are 
further possible locations. ${ }^{2}$ The incidence of squamous cell carcinoma has doubled in the last three decades in United States and approximately $2 \%$ of those affected die from this disease. ${ }^{2}$ Most of the cases of oral and throat SCC are diagnosed at a late stage. The prevalence of SCC is higher in Pakistan and other South East Asian nations. ${ }^{3}$ Risk of this cancer is intensified by direct and prolonged exposure to sunlight. ${ }^{4}$ Patients presenting with squamous cell carcinoma unveil discrepancies in their signs and symptoms and response to treatment. The common age at diagnosis of SCC of skin is 8th decade of life. ${ }^{5}$ Males are more affected by this disease as compared to females. Like any malignancy, it affects bone marrow and decreases hemopoiesis as well. Fibrinolytic system is activated in SCC cases at subclinical and clinical stages. The biological consequences of the haemostatic deviations in squamous cell carcinoma are imprecise. There is evidence that malignant cells activate the coagulation system with an increase in fibrinolytic activity. This may result in increased metastatic activities leading to DIC. $^{6}$ So it is multifaceted interaction between pathologic mechanism of thrombosis, tumor cells and haemostatic system. ${ }^{7}$ Plasma concentration of Ddimer is increased in malignancy due to activation of fibrinolytic system. ${ }^{8}$ Raised levels of prothrombin time (PT), Activated partial thromboplastin time (APTT), thrombin time (TT), low Anti thrombin-III activity and increased fibrin degradation products (FDP) indicates disseminated intravascular coagulation..$^{9-11}$ Tumor cells lead to activation of coagulation system either directly, by release of procoagulants from tumor cells, or indirectly, through production of tumor cells cytokines that trigger procoagulant substances in the systemic circulation by monocytes, macrophages and endothelial cells. ${ }^{12}$

The bleeding and/or thrombosis in advanced stage cancer provides need for a research in blood coagulation abnormalities in malignancy. This study is intended to detect coagulation abnormalities that lead to disseminated intravascular coagulation and might predict hemorrhagic or thrombotic complications. ${ }^{13}$ Thromboembolic disease is a common complication of malignancy which occurs due to disturbance in haemostatic balance comprising interactions between endothelial cells, thrombocytes, coagulation, and fibrinolysis. Lack of early and prompt diagnosis of DIC leads to development of lethal complications and bleeding diathesis. Therefore, DIC screening is associated with a reduction in mortality in patients presenting with sepsis. The aim of this study was to determine the relationship between the hematological and coagulation parameters with various morphological grades of squamous cell carcinoma.

\section{Material and Methods}

This cross-sectional study was conducted in the Pathology department of Isra University Hospital. Both male and female patients of all age groups having SCC of skin, gastrointestinal and genital tract were selected through non probability convenient sampling. Study duration was 6 months from May 2017 to October 2017. Patients with chronic comorbidities like skin infections, congenital haematological abnormalities and those on chemotherapy were excluded.

Using aseptic techniques, approximately $3 \mathrm{ml}$ whole blood was collected by venipuncture in citrated bottles. Plasma was separated by centrifuging at $2000 \mathrm{rpm}$ for 10 minutes, and stored at $-24^{\circ} \mathrm{C}$ until analysis. The coagulation profile was analyzed by Sysmax ca 50 coagulation analyzer and NycoCard Reader II.

Data was analyzed using SPSS version 22.0. Frequency and percentages were calculated for qualitative variables. ANOVA test was applied for comparison of more than 2 variables like prothrombin time (PT), Activated partial thromboplastin time (APTT), thrombin time (TT), 
Anti thrombin-III activity and D-dimers. P-value $<0.05$ was taken as statistically significant.

\section{Results}

In this study mean age of the patients was $55.5 \pm 12$ years, with an age range of $23-80$ years. Most of the patients were males $(n=81 ; 64.3 \%)$ as compared to females ( $n=45 ; 35.8 \%$ ). Majority of the patients were found with well differentiated (42.1\%) and moderately differentiated SCC (40.5\%), while poorly differentiated SCC was found only in $17.4 \%$. Oral SCC (43.7\%) was the most common site of squamous cell carcinoma followed by esophageal $\operatorname{SCC}(28.6 \%)$ (Table I).

\begin{tabular}{|l|c|}
\hline \multicolumn{2}{|c|}{$\begin{array}{c}\text { Table I: Distribution of squamous cell carcinoma } \\
\text { cases according to site }(\mathbf{n = 1 2 6})\end{array}$} \\
\hline Site & $\mathbf{n}(\mathbf{\%})$ \\
\hline Oral cavity & $55(43.7)$ \\
\hline Esophagus & $36(28.6)$ \\
\hline Skin & $14(11.1)$ \\
\hline Cervix & $13(10.3)$ \\
\hline Anus & $5(3.9)$ \\
\hline Vagina & $3(2.3)$ \\
\hline
\end{tabular}

The coagulation profile comprising the PT, APTT, clotting time, bleeding time, D-dimer, fibrinogen and thrombin time was compared with histological grades of SCC (Table II). The mean prothrombin time increased significantly from $15.22 \pm 3.71$ seconds in well differentiated SCC to $24.01 \pm 2.9$ seconds in poorly differentiated squamous cell carcinoma $(P=0.01)$. Similarly, the mean APTT $(P=0.001)$, bleeding time $(P=0.05)$, clotting time $(P=0.05)$, thrombin time $(P=0.01)$ and D-Dimers $(P=0.01)$ showed a significant increase from well differentiated SCC to poorly differentiated SCC (Table II). However, Fibrinogen levels decreased as tumor progressed from well differentiated to poorly differentiated grade $(P=0.001)$ (Table II).

\section{Discussion}

In this study, the coagulation profile (PT, APTT, BT, $\mathrm{CT}$, TT, fibrinogen, D-dimer) is found deranged in accordance with the different histological grades of SCC. The deranged values were more pronounced in poorly differentiated squamous cell carcinoma. These results are in accordance with the study conducted by Tas et $\mathrm{al}^{15}$ who reported elevated plasma levels of D-dimer, fibrinogen, PT, APTT and INR in lung cancer patients. In the present study, significant alteration was seen in BT and $\mathrm{CT}$, which is parallel with the study conducted by Engheta et al. ${ }^{16}$ who also conveyed similar findings. Zhang et al. and $L i$ et al. reported that the triggered hemostatic system for instance, hyperfibrinogenemia and higher D-dimer levels are found in SCC which is parallel with the present revision. ${ }^{17,18}$ Studies by Liu et al. and Feng et al. also found increased plasma levels of D-dimer in SCC patients, which is consistent with the current study. ${ }^{19,20}$ However, the current study also assessed the D-dimer levels in squamous cell carcinoma patients on the basis of grading.

Study conducted by Nakano et al. altered levels of blood coagulation factors in different pathologic types of lung cancer. ${ }^{21}$ In addition fibrin/fibrinogen degradation products, fibrinogen, and D-dimer levels differed significantly between cancer patients and the control group. These findings are consistent with our study which also showed raised level of D-dimer and PT in different histopathologic types of squamous cell carcinoma.

The result of the present study shows significantly increased levels of D-dimer in different histologic types of squamous cell carcinoma. These findings are similar to a study by Luo et al who also reported increased level of D-dimer for different histologic grades of squamous cell carcinoma. ${ }^{22}$ Mariani et al. also showed raised levels of PT, APTT, and TT indicating hypercoagulability with significantly 


\begin{tabular}{|c|c|c|c|c|}
\hline \multicolumn{5}{|c|}{ Table II: Comparison of coagulation profile with histological grades of squamous cell carcinoma ( $n=126)$} \\
\hline Groups & \multicolumn{2}{|c|}{ Prothrombin Time } & F-value & P-value* \\
\hline WD vs MD & $15.22 \pm 3.71$ & $16.33 \pm 2.55$ & \multirow{3}{*}{4.49} & 0.82 \\
\hline WD vs PD & $15.22 \pm 3.71$ & $24.01 \pm 2.90$ & & 0.01 \\
\hline \multirow[t]{2}{*}{ PD vs MD } & $24.01 \pm 2.90$ & $16.33 \pm 2.55$ & & 0.03 \\
\hline & \multicolumn{2}{|c|}{ APTT } & \multirow{4}{*}{7.49} & \\
\hline WD vs MD & $35.10 \pm 9.10$ & $37.36 \pm 13.89$ & & 0.08 \\
\hline WD vs PD & $35.10 \pm 9.10$ & $43.39 \pm 13.68$ & & 0.001 \\
\hline PD vs MD & $43.39 \pm 13.68$ & $37.36 \pm 13.89$ & & 0.01 \\
\hline \multirow[b]{2}{*}{ WD vs MD } & \multicolumn{2}{|c|}{ Bleeding Time } & \multirow{4}{*}{2.60} & \\
\hline & $3.40 \pm 0.73$ & $5.44 \pm 0.63$ & & 0.01 \\
\hline WD vs PD & $3.40 \pm 0.73$ & $6.17 \pm 0.42$ & & 0.05 \\
\hline \multirow[t]{2}{*}{ PD vs MD } & $6.17 \pm 0.42$ & $5.44 \pm 0.63$ & & 0.82 \\
\hline & \multicolumn{2}{|c|}{ Clotting Time } & \multirow{4}{*}{2.58} & \\
\hline WD vs MD & $4.88 \pm 0.89$ & $5.22 \pm 1.25$ & & 0.99 \\
\hline WD vs PD & $4.88 \pm 0.89$ & $6.93 \pm 1.32$ & & 0.05 \\
\hline PD vs MD & $6.93 \pm 1.32$ & $5.22 \pm 1.25$ & & 0.72 \\
\hline \multirow[b]{2}{*}{ WD vs MD } & \multicolumn{2}{|c|}{ D-Dimers } & \multirow{4}{*}{2.49} & 087 \\
\hline & $0.74 \pm 0.16$ & $0.83 \pm 0.23$ & & 0.82 \\
\hline WD vs PD & $0.74 \pm 0.16$ & $1.01 \pm 0.31$ & & 0.01 \\
\hline \multirow[t]{2}{*}{ PD vs MD } & $1.01 \pm 0.31$ & $0.83 \pm 0.23$ & & 0.03 \\
\hline & \multicolumn{2}{|c|}{ Fibrinogen } & \multirow{4}{*}{5.46} & 005 \\
\hline WD vs MD & $174.75 \pm 20.8$ & $186.58 \pm 18.1$ & & \\
\hline WD vs PD & $174.75 \pm 20.8$ & $227.9 \pm 22.1$ & & 0.001 \\
\hline PD vs MD & $227.9 \pm 22.1$ & $186.58 \pm 18.1$ & & 0.001 \\
\hline \multirow[b]{2}{*}{ WD vs MD } & & & \multirow{4}{*}{2.09} & \\
\hline & $50.11 \pm 7.92$ & $45.18 \pm 6.68$ & & 0.08 \\
\hline WD vs PD & $50.11 \pm 7.92$ & $82.51 \pm 5.74$ & & 0.01 \\
\hline PD vs MD & $82.51 \pm 5.74$ & $45.18 \pm 6.68$ & & 0.01 \\
\hline
\end{tabular}

* $P$-value $<0.05$ was considered statistically significant. $W D=$ Well-differentiated, $M D=$ Moderately-differentiated, $\mathrm{PD}=$ Poorly-differentiated, vs=versus, $\mathrm{APTT}=$ activated partial thromboplastin time

F-value $=$ used in analysis of variance (ANOVA) to determine whether the test is statistically significant

decreased levels of platelets in lung cancer patients. ${ }^{23}$ The D-dimer levels remained unchanged. These findings are consistent with our study, except D-dimer, as all the coagulation markers significantly increased as the severity of histological grade of squamous cell carcinoma increased from well differentiated to poorly differentiated cancer.
The main limitation of this study was that immunomarkers for confirmation of doubtful cases were not applied due to financial constraints. Another limitation was that the results cannot be generalized as comparatively lower number of SCC cases were studied with an unequal distribution of cancers arising from different sites.

\section{Conclusion}

The different coagulation profile parameters like PT, APTT, BT, CT, D-dimer and TT are elevated in SCC, with a decrease in fibrinogen levels, proportional to the severity of the histological grade. 
Recommendations: Changes in hemostasis play an important role in anticipation of future hemorrhagic manifestation and thrombotic event during cancer progression. Early workup for presence of coagulation abnormalities will prevent mortality and other bleeding diathesis in cancer, as alterations in coagulation pathway leads to lethal complication of hemostasis.

\section{References}

1. Brianti P, De Flammineis E, Mercuri SR. Review of HPV-related diseases and cancers. New Microbiol. 2017; 40(2): 80-5. PMID: 28368072

2. Sánchez-Danés A, Blanpain C. Deciphering the cells of origin of squamous cell carcinomas. Nat Rev Cancer. 2018; 18(9): 549-61. Doi: 10.1038/s41568018-0024-5

3. Qamar S, Fatima S, Rehman A, Khokhar MA, Mustafa Z, Awan N. Glucose Transporter 1 Overexpression in Oral Squamous Cell Carcinoma. J Coll Physicians Surg Pak. 2019; 29(8): 724-27. Doi: 10.29271/ jcpsp.2019.08.724

4. Diepgen $T$, Fartasch $M$, Drexler $H$, Schmitt J. Occupational skin cancer induced by ultraviolet radiation and its prevention. Brit J Dermatol. 2012; 167: 76-84.

5. Shaikh AH, Mohammad T, Qureshi NR. Histopathological Patterns of oral squamous cell carcinoma. PODJ. 2014; 34(3): 449-51.

6. Falanga A, Schieppati F, Russo L. Pathophysiology 1. Mechanisms of Thrombosis in Cancer Patients. In: Thrombosis and Hemostasis in Cancer. 2019 (pp. 1136). Springer, Cham.

7. Nadir Y, Brenner B. Cancer and Thrombosis-New Insights. Rambam Maimonides Med J. 2018 Oct;9(4); e0033. Doi: 10.5041/RMMJ.10349

8. Masago K, Fujita S, Mio T, Togashi Y, Kim YH, Hatachi $Y$, et al. Clinical significance of the ratio between the alpha 2 plasmin inhibitor-plasmin complex and the thrombin-antithrombin complex in advanced nonsmall cell lung cancer. Med Oncol. 2011; 28(1): 3516. Doi: 10.1007/s12032-010-9454-y

9. Vincent $\mathrm{JL}$, Castro $P$, Hunt $B J$, Jörres $A$, Praga $M$, Rojas-Suarez J, et al. Thrombocytopenia in the ICU: disseminated intravascular coagulation and thrombotic microangiopathies-what intensivists need to know. Crit Care. 2018; 22(1):158. Doi: 10.1186/s13054-018-2073-2

10. Khorana AA. Malignancy, thrombosis and trousseau: the case for an eponym. J Thromb Haemost. 2003; 1(12): 2463-5. Doi: 10.1111/j.1538-7836.2003. 00501.x

11. Falanga $A$, Marchetti $M$, Vignoli A. Coagulation and cancer: biological and clinical aspects. J Thromb Haemost. 2013; 11(2): 223-33. Doi: 10.1111/ jth.12075

12. Ujjan ID, Khokhar NA, Shaikh MA, Shaikh IA, Memon RA, Maheshwari N. Evaluation of Coagulation Abnormalities in Lung Cancer Patients. JLUMHS. 2009; 8(02): 118-20.

13. Zhang $X$, Chen G, Li J. Relationships between coagulation indicators and clinicopathological characteristics of patients with esophageal squamous-cell carcinoma. Shandong Medical Journal. 2017; 2017(22): 5.

14. Wu Y. Contact pathway of coagulation and inflammation. Thrombosis J. 2015; 13(1): 17. Doi: 10.1186/s12959-015-0048-y

15. Tas F, Kilic L, Serilmez M, Keskin S, Sen F, Duranyildiz D. Clinical and prognostic significance of coagulation assays in lung cancer. Resp Med. 2013; 107(3): 4517. Doi: 10.1016/j.rmed.2012.11.007

16. Engheta A, Abianeh SH, Atri A, Sanatkarfar M. Aspirin use and bleeding volume in skin cancer patients undergoing surgery: a randomized controlled trial. DARU. 2016; 24(1): 20. Doi: 10.1186/s40199-016-0159-4

17. Zhang $F$, Wang $Y$, Sun $P$, Wang ZQ, Wang DS, Zhang DS, et al. Fibrinogen promotes malignant biological tumor behavior involving epithelial-mesenchymal transition via the $\mathrm{p}-\mathrm{AKT} / \mathrm{p}-\mathrm{mTOR}$ pathway in esophageal squamous cell carcinoma. J Cancer Res Clin Oncol. 2017; 143(12): 2413-24. Doi: 10.1007/s00432-017-2493-4

18. Li J, Zheng Z, Fang M. Impact of pretreatment plasma D-dimer levels and its perioperative change on prognosis in operable esophageal squamous cell carcinoma. Oncotarget. 2017; 8(45): 79537-545. Doi: 10.18632/oncotarget.18552

19. Liu DQ, Li FF, Jia WH. Cumulative scores based on plasma D-dimer and serum albumin levels predict survival in esophageal squamous cell carcinoma 
patients treated with transthoracic esophagectomy. Chin J Cancer. 2016; 35(1): 11. Doi: 10.1186/s40880015-0062-2

20. Feng JF, Yang $X$, Chen S, Zhao $Q$, Chen $Q X$. Prognostic value of plasma D-dimer in patients with resectable esophageal squamous cell carcinoma in Chin J Cancer. 2016; 7(12):1663-67. Doi: 10.7150/jca.15216

21. Nakano K, Sugiyama K, Satoh H, Shiromori S, Sugitate $\mathrm{K}$, Arifuku $\mathrm{H}$, et al. Risk factors for disseminated intravascular coagulation in patients with lung cancer. Thorac cancer. 2018; 9(8): 931-8. Doi: 10.1111/1759-7714.12766

22. Luo YL, Chi PD, Zheng $X$, Zhang L, Wang XP, Chen $H$. Preoperative $D$-dimers as an independent prognostic marker in cervical carcinoma. Tumour Biol. 2015; 36(11): 8903-11. Doi: 10.1007/s13277015-3650-5

23. Mariani $M$, Hariman $H$, Soeroso NS. Hypercoagulability in patients with lung cancer undergoing chemotherapy. Indones J Clinical Pathol Med Laboratory. 2018; 24(3): 210-4 